\title{
Safety of the LCP Pediatric Hip Plate in Proximal Femoral Osteotomy in Children with Cerebral
} Palsy

This article was published in the following Dove Press journal: Journal of Multidisciplinary Healthcare

\author{
Omar Q Samarah' \\ Majd A Shaheen ${ }^{2}$ \\ Rana A Tehabsim² \\ Bayan A Shaheen ${ }^{2}$ \\ Marah B Makahleh ${ }^{2}$ \\ Mahmoud M Almustafa $\mathbb{( D}^{3}$ \\ Fadi A Al hadidi \\ Lutfi A Hussein' \\ Yazan S Hammad (iD) \\ 'Department of Special Surgery, School \\ of Medicine, University of Jordan, \\ Amman, Jordan; ${ }^{2}$ School of Medicine, \\ University of Jordan, Amman, Jordan; \\ ${ }^{3}$ Department of Anesthesia, School of \\ Medicine, University of Jordan, Amman, \\ Jordan
}

Correspondence: Omar Q Samarah Department of Special Surgery, School of Medicine, University of Jordan, Queen Rania Street, Amman, Jordan 11942

Tel +96265353444 ext. 245I

Fax +96265353338

Email o.samarah@ju.edu.jo
Purpose: Proximal femoral osteotomy in cerebral palsy patients is a demanding procedure. The fixation of the osteotomy can fail due to the weak osteoporotic bone. The LCP pediatric hip plate with its good grip makes these procedures safe. The aims of the present study are to evaluate the radiological outcome of proximal femoral osteotomy that was fixed with the pediatric LCP in cerebral palsy patients and to raise safety issues regarding its low rate of complications.

Patients and Methods: Sixteen patients with cerebral palsy who were operated in our department were included in this retrospective study. Data collected from medical charts and $\mathrm{X}$-ray measurements retrospectively reviewed.

Results: In total, 16 patients (21 hips), ie, 9 males and 7 females, were included in this analysis. The mean age at the time of the index surgery was 11.9 years (5.9-18.0). The mean follow-up period was 4.78 years (1.5-8.0). Five patients had bilateral hip involvement and 11 had unilateral involvement. All patients had spastic cerebral palsy. The mean values of varus correction and de-rotation were $25^{\circ}\left(0^{\circ}-45^{\circ}\right)$ and $35^{\circ}\left(20^{\circ}-50^{\circ}\right)$, respectively. Neck shaft angle and the Reimer's migration index were significantly improved postoperatively $(\mathrm{p}<0.01$ for both). Seventeen hips showed complete consolidation within 14 weeks of fixation and four hips needed 16 weeks. These four hips were in three patients who were 16 years of age or older. The correlation between age at surgery and the time needed for consolidation was statistically significant $(\mathrm{p}=0.005)$. Avascular necrosis, revision surgeries, failure of fixation, acetabular penetration, screw loosening or fracture of the femur were not seen in this study. Conclusion: The LCP pediatric hip plate can be used safely in CP patients. The plate provides a strong stable fixation on osteoporotic bone with a low rate of complications.

Keywords: hip plate, neurological disorder, cerebral palsy, osteotomy, jordan

\section{Introduction}

Hip problems are common in cerebral palsy (CP) patients. Risk of hip displacement progression correlates with an increase in disease severity based on the Gross Motor Function Classification System (GMFCS) level, which may reach up to $66 \%{ }^{1,2}$ Abnormal muscle functions across the hip joint lead to different pathological changes seen in CP patient hips, ranging from persistent hip anteversion and hip subluxation to frank dislocation of the hip joints. ${ }^{3}$ The optimal treatment strategies for such pathologies in $\mathrm{CP}$ patients are still controversial. ${ }^{4}$ Proximal femoral osteotomy (PFO) is a well-established procedure and an option to correct these deformities and maintain the hip in the acetabulum. 
The improvements achieved in implant design have decreased the rate of the implant-related complications. This allows for early motion and avoids hip spica application, which may aggravate bone weakness. Patients with CP are also known to have weak osteoporotic bone that may jeopardize the fixation method. Different complications have been raised in the literature following inter- and subtrochanteric PFOs, such as metal cut out, loss of correction, wound infection, hematoma formation, femur neck fractures, heterotopic ossification and metal breakage. ${ }^{5-7}$

The locking pediatric hip plate system has been shown to have an improvement in the fixation strength and stability through the use of locking screws, in addition to a decrease in the loosening rate in weak osteoporotic bones. ${ }^{3,6}$

At our university hospital, the LCP pediatric hip plate (DePuy Synthes - Oberdorf Switzerland) has been used since late 2011. The aim of using this plate is to allow early mobilization and avoid hip spica application in CP patients when possible.

The aim of the current study was to retrospectively evaluate the radiological outcome of PFOs fixed with the pediatric LCP in CP patients, in terms of bony consolidation and stability of fixation. In addition to that, we aimed to evaluate the reliability of using the LCP plate in neurological disorders and to raise safety issues regarding the low rate of eventual complications.

\section{Patients and Methods}

\section{Patient Selection}

We reviewed retrospectively the medical chart and the radiographs of all children, who underwent proximal femoral osteotomy and who were fixed with an LCP pediatric hip plate at our hospital between 2011 and 2017. This review identified a total of 54 patients. Thirtythree patients had other underlying pathologies like residual deformities of developmental dysplasia of the hip, malalignment syndromes and myelomeningocele and were all excluded from this study. Twenty-one patients had spastic cerebral palsy. Four of the CP patients had less than one year of follow-up, and one has been lost to follow-up due to incomplete data in the medical chart. At the end of the study, 16 patients fulfilled the three inclusion criteria and were enrolled in this study.

Patients with spastic cerebral palsy.

Underwent PFO that had been fixed with the LCP pediatric hip plate.

Follow-up period of at least 18 months.
Ethical approval to conduct this study was obtained from the institutional review board (IRB) of Jordan University Hospital (JUH), with approval reference number $67 / 2019 / 1844$. This study was performed according to the declaration of Helsinki. Patient consent was not needed because of the retrospective nature of the study. In addition to that, the IRB of JUH provides the principle researcher an access to review patient's records without having their consent for the use in the approved research purposes, provided that:

No patient identification data revealed in the study.

The data use should be restricted for the study purpose approved by the IRB committee.

\section{Outcome Measures}

The index procedure was associated with pelvic osteotomy and/or multilevel soft tissue release (SEMLS) based on the preoperative clinical and radiological findings (Table 1). Age of the patient at surgery, gender, anatomic classification of $\mathrm{CP}$, functional classification, associated surgeries and any complication related to the surgery or to implant used for fixation were collected and analyzed (Tables 2 and 3).

Radiographically, two anteroposterior (AP) pelvic $\mathrm{X}$-ray views were taken preoperatively (neutral AP view and AP view in internal hip rotation) to visualize the true neck-shaft angle (NSA) and compensate for the femoral anteversion angle, immediately postoperatively, as well as 6 and 12 weeks postoperatively, in addition, another $\mathrm{X}$-ray was taken at 16 weeks postoperatively if no consolidation was seen prior to that and finally at the last follow-up visit. Consolidation was assessed by three criteria: invisible osteotomy gap, as well as medial and lateral callus formation. Consolidation was considered complete if all three signs were positive, and incomplete if only one or two signs were positive. The absence of all these signs indicated no consolidation. ${ }^{6}$ The following radiographic parameters were evaluated: NSA, Reimer's migration index (RMI) and time to radiographic bone consolidation. All measurements were carried out by the main author.

\section{Statistical Analysis}

The data were analyzed using PASW Statistics 18 (IBM, USA). Repeated measures ANOVA for parametric data and the Friedman test for non-parametric data were used. The correlations were examined by Spearman correlation. 
Table I Spica Use and Associated Surgeries

\begin{tabular}{|l|l|l|l|}
\hline Number & Index Procedure & Spica Use & Associated Surgeries \\
\hline 1 & PFO & No & Lengthening of hamstring tendon, adductor and flexor tenotomy \\
2 & PFO & No & Bilateral lengthening of hamstring tendon, bilateral adductor tenotomy \\
3 & PFO & No & - \\
4 & PFO & No & - \\
5 & PFO & Yes & Dega osteotomy \\
6 & PFO & No & Lengthening of hamstring tendon and adductor tenotomy \\
7 & PFO & No & - \\
8 & PFO & Yes & Lengthening of hamstring tendon, adductor tenotomy, dega osteotomy, femoral shortening osteotomy \\
9 & PFO & Yes & Lengthening of hamstring tendon \\
10 & PFO & No & Lengthening of hamstring tendon, gastrocnemius slide \\
11 & PFO & No & Bilateral hamstring release, bilateral adductor release, bilateral gastrocnemius slide \\
12 & PFO & No & - \\
13 & PFO & No & - \\
14 & PFO & No & - \\
15 & PFO & No & Lengthening of hamstring tendon \\
16 & PFO & No & Gastrocnemius slide \\
17 & PFO & No & Lengthening of hamstring tendon and flexor tenotomy \\
18 & PFO & No & Lengthening of hamstring tendon, adductor tenotomy \\
19 & PFO & No & - \\
20 & PFO & No & Lengthening of hamstring tendon, gastrocnemius slide \\
21 & PFO & No & Lengthening of hamstring tendon \\
\hline
\end{tabular}

\section{Results}

A total of 16 patients were included in this analysis. There were nine males and seven females. Twenty-one hips were operated on, including eight hips on the right side and 13 on the left side. The mean age at the time of the index surgery was 11.9 years (5.9-18.0). The mean followup period was 4.78 years $(1.5-8.0)$. Five patients had bilateral hip involvement and 11 had unilateral involvement. All patients had spastic cerebral palsy. Among them, five patients (31.3\%) were hemiplegic, 9 (56.2\%) were diplegic and only two patients $(12.5 \%)$ were quadriplegic. According to the GMFCS, none of the patients had level I gross motor function. Levels II, III, IV and V were seen in $18.75 \%, 68.75 \%, 6.25 \%$ and $6.25 \%$, respectively. Varus correction was performed in all patients except one patient, in whom the preoperative pelvic X-ray view in internal hip rotation showed complete acetabular coverage of the femoral head. The mean value of varus correction was $25^{\circ}\left(0^{\circ}-45^{\circ}\right)$. De-rotation was also carried out in all patients with a mean of $35^{\circ}\left(20^{\circ}-50^{\circ}\right)$. Figures 1 and 2 show radiographs of 2 patients with GFMCS III and V successively. In all patients, the NSA improved significantly postoperatively; the mean value decreased from $153^{\circ}$ preoperatively to $128^{\circ}$ postoperatively and was maintained at $129^{\circ}$ at the last follow-up. This showed a statistically significant difference in the mean value of the NSA between the preoperative and postoperative values $(p<0.01)$. Moreover, comparing the last follow-upvalue with the preoperative value, statistical significance was also evident $(\mathrm{p}<0.01)$. The RMI was also improved postoperatively, where the mean value decreased from $31 \%$ preoperatively to $14 \%$ postoperatively. This difference also showed statistical significance $(p<0.01)$. The same statistical difference was evident at the last followup measurement $(\mathrm{p}<0.01)$. Both NSA and RMI showed a statistically non-significant difference between the postoperative and the last follow-up-values (p-values $=1.000$ and 0.135 , respectively), indicating stability of fixation. Seventeen hips showed complete consolidation within 14 weeks of fixation, only four hips needed 16 weeks to show full consolidation of the osteotomy site. These four hips were in three patients who were 16 years of age or older at the time of the index procedure. The Spearman's rho correlation between age at surgery and the needed time for consolidation was 0.588 , which was statistically significant $(\mathrm{p}=0.005)$; thus, surgery at an older age was associated with delayed time to reach consolidation.

There was no reoperation concerning the plate system. None of the patients developed avascular necrosis following the surgery. Two patients, those with quadriplegia, had 
Table 2 Demographic and Radiological Data

\begin{tabular}{|c|c|c|c|c|c|c|c|c|c|c|c|c|}
\hline \multirow{2}{*}{ Number } & \multirow{2}{*}{$\begin{array}{l}\text { Age at Surgery } \\
\text { (y) }\end{array}$} & \multirow[t]{2}{*}{ Gender } & \multirow[t]{2}{*}{ Side } & \multirow{2}{*}{$\begin{array}{l}\text { Follow-Up } \\
\text { (y) }\end{array}$} & \multicolumn{3}{|c|}{ NSA X-ray } & \multicolumn{3}{|c|}{ Reimers Index } & \multirow{2}{*}{$\begin{array}{l}\text { Varus } \\
\text { Angle }\end{array}$} & \multirow[t]{2}{*}{ Derotation } \\
\hline & & & & & Pre & Post & Final & Pre & Post & Final & & \\
\hline 1 & 13.5 & $M$ & $\mathrm{R}$ & 8 & 145 & 135 & 130 & 0.23 & 0.18 & 0.18 & 10 & 20 \\
\hline 2 & 8 & $\mathrm{~F}$ & $\mathrm{R}$ & 7 & 165 & 125 & 132 & 0.2 & 0.16 & 0.16 & 40 & 30 \\
\hline 3 & 8.5 & $\mathrm{~F}$ & $\mathrm{~L}$ & 6.5 & 160 & 135 & 127 & 0.2 & 0.12 & 0.1 & 20 & 30 \\
\hline 4 & 11.7 & $\mathrm{~F}$ & $\mathrm{R}$ & 5.5 & 160 & 130 & 130 & 0.2 & 0.16 & 0.16 & 30 & 30 \\
\hline 5 & 6 & $\mathrm{~F}$ & $\mathrm{~L}$ & 3.5 & 150 & 104 & 128 & 0.4 & 0.08 & 0.06 & 45 & 40 \\
\hline 6 & 12.9 & $M$ & $\mathrm{~L}$ & 4.5 & 165 & 140 & 140 & 0.3 & 0.16 & 0.16 & 25 & 40 \\
\hline 7 & 13.6 & $M$ & $\mathrm{R}$ & 4 & 160 & 140 & 145 & 0.25 & 0.11 & 0.16 & 20 & 40 \\
\hline 8 & 5.9 & $M$ & $\mathrm{~L}$ & 4 & 160 & 120 & 120 & I & 0 & 0.13 & 40 & 40 \\
\hline 9 & 8 & $M$ & $\mathrm{R}$ & 2 & 160 & 130 & 130 & 0.6 & 0.2 & 0.2 & 40 & 40 \\
\hline 10 & 18 & $M$ & $\mathrm{~L}$ & 1.5 & 140 & 125 & 130 & 0.22 & 0.17 & 0.13 & 15 & 30 \\
\hline 11 & 17 & $M$ & $\mathrm{R}$ & 6 & 155 & 130 & 133 & 0.21 & 0.06 & 0 & 25 & 35 \\
\hline 12 & 8.5 & $M$ & $R$ & 4 & 145 & 119 & 116 & 0.35 & 0.2 & 0.17 & 30 & 30 \\
\hline 13 & 14 & $M$ & $\mathrm{~L}$ & 8 & 140 & 122 & 119 & 0.5 & 0.3 & 0.2 & 10 & 30 \\
\hline 14 & 12.3 & $F$ & $\mathrm{~L}$ & 5 & 155 & 130 & 140 & 0.2 & 0.16 & 0.16 & 25 & 30 \\
\hline 15 & 16 & $M$ & $\mathrm{~L}$ & 4 & 148 & 125 & 123 & 0.2 & 0.16 & 0.14 & 25 & 40 \\
\hline 16 & 18 & $M$ & $\mathrm{~L}$ & 3.5 & 146 & 124 & 124 & 0.16 & 0.08 & 0.07 & 20 & 40 \\
\hline 17 & 14.5 & $M$ & $R$ & 6 & 160 & 125 & 125 & 0.4 & 27 & 20 & 35 & 30 \\
\hline 18 & 8 & $\mathrm{~F}$ & $\mathrm{~L}$ & 3.5 & 140 & 140 & 140 & 0.24 & 0 & 0 & 0 & 40 \\
\hline 19 & 16 & $\mathrm{~F}$ & $\mathrm{~L}$ & 8 & 150 & 120 & 120 & 0.25 & 0.18 & 0.15 & 30 & 50 \\
\hline 20 & 9 & $\mathrm{~F}$ & $\mathrm{~L}$ & 2 & 155 & 130 & 127 & 0.26 & 0.15 & 0.15 & 25 & 25 \\
\hline 21 & 11 & $\mathrm{~F}$ & $\mathrm{~L}$ & 4 & 155 & 135 & 133 & 0.13 & 0.1 & 0.1 & 20 & 35 \\
\hline
\end{tabular}

Abbreviation: NSA, neck-shaft angle.

pain during the follow-up period, mainly during manipulation by caregivers. One patient had a superficial surgical site infection two years after the index procedure. None of the patients had failure of fixation, acetabular penetration, screw loosening or fracture of the femur during the entire follow-up period. All patients achieved complete consolidation at the final follow-up radiological evaluation.

\section{Discussion}

Several implants have been used to fix PFO in pediatric patients with good results, although some complications had been reported. Of these, a loss of fixation, wound problems, hardware prominence, loosening and femur fracture are the most important. ${ }^{5,8}$ The LCP plate has a low lateral profile that avoids the problem of prominent metal seen in the blade plate. ${ }^{5}$ Moreover, it has a low risk of disturbances to periosteal blood supply due to the low bone-plate contact while using locking screws. ${ }^{9}$ Stability of fixation is another advantageous feature of the LCP plate in children with poor bone quality including neuromuscular disorders, compared to the fixed angled blade plate as reported in several published papers. ${ }^{5,6}$ Lack of medialization and subsequent change in the proximal femoral biomechanics might be a disadvantage of LCP hip plate. This drawback has been resolved by using a special instrument, which can be used intraoperatively with the preplanned translation to improve the hip biomechanics as described by Joeris et al. ${ }^{9}$

Our collected data after using a locking pediatric hip plate system to fix PFOs in CP patients showed both the effectivity and safety of the system. Maintenance of stability was evident throughout the follow-up period. All osteotomies followed a smooth course of union without any loss of fixation. Similar results had been seen in previous published data that used same plate system. ${ }^{3,10}$ This advantageous feature of stability makes this locking plate distinguishable when compared to other plates that showed loss of fixation in proximal femoral osteotomy, as reported by previous publications. ${ }^{5,6,11}$ The LCP pediatric hip plate system provides an accurate correction of the proximal femoral deformity based on preoperative planning and the utilization of the positioner aiming block.

Healing of the osteotomy went uneventfully. All cases showed early callus formation at 6 weeks postoperatively and the majority (17 hips in 14 patients) showed consolidation at 14 weeks postoperatively. Four hips needed 16 weeks to achieve complete bony consolidation. This was correlated to the older age of the patients, in addition to the rigidity of fixation and the angular stability of the plate-screw system 
Table 3 Anatomical and Functional Classification of CP

\begin{tabular}{|c|c|c|c|c|}
\hline \multirow[t]{2}{*}{ Number } & \multicolumn{3}{|l|}{ Diagnosis } & \multirow{2}{*}{$\begin{array}{l}\text { GMFCS } \\
\text { Level (I- } \\
\text { V) }\end{array}$} \\
\hline & Hemiplegic & Diplegic & Quadriplegic & \\
\hline I & & $x$ & & III \\
\hline 2 & & $x$ & & III \\
\hline 3 & & $x$ & & III \\
\hline 4 & & $x$ & & II \\
\hline 5 & & & $x$ & IV \\
\hline 6 & & $x$ & & III \\
\hline 7 & & $x$ & & III \\
\hline 8 & & & $x$ & $V$ \\
\hline 9 & & & $x$ & $\mathrm{~V}$ \\
\hline 10 & & $x$ & & III \\
\hline II & $x$ & & & III \\
\hline 12 & $x$ & & & II \\
\hline 13 & $x$ & & & II \\
\hline 14 & & $x$ & & II \\
\hline 15 & & $x$ & & III \\
\hline 16 & & $x$ & & III \\
\hline 17 & $x$ & & & III \\
\hline 18 & & $x$ & & III \\
\hline 19 & $x$ & & & III \\
\hline 20 & & $x$ & & III \\
\hline 21 & & $x$ & & III \\
\hline
\end{tabular}

provided by the LCP plate. ${ }^{6}$ At the final follow-up, complete consolidation was achieved without any case of non-union.

Both NSA and Reimers migration index improved significantly postoperative and nearly maintained at the final followup-value with significant difference (p-value $<0.01$ ) Statistically, no significant changes were seen between the immediate postoperative and the final NSA, which indicates the stability of fixation with a p-value of $<0.01$. All hips were stable at the final follow-up. This primary stability and maintenance of osteotomy correction achieved by the LCP plate system had been addressed in several previous publications. ${ }^{6,9,10}$

Primary stability achieved using this plate system avoids cast immobilization postoperatively, which protects the bone from further weakness and facilitates rehabilitation and care for the patient's caregivers. An exception to this were patients who underwent a combined pelvic surgery that necessitated the use of a hip spica. We used the hip spica in two patients of our series, as a modified dega osteotomy was used to address the acetabular dysplasia in these patients. These two patients were GFMCS IV and V. None of patients with GFMCS I, II and III had a hip spica. Despite that, no complications of hip spica use were seen in these patients. A literature review showed several complications of spica use postoperatively in $\mathrm{CP}$ patients, including femur fractures and pressure sores. ${ }^{10,12}$

Loosening of the locking screws was not observed in our case series nor in previously published papers. ${ }^{3,6}$ One publication reported the loosening of all three femur shaft screws due to technical failure of the DC holes rather than the locking holes themselves. ${ }^{9}$

Avascular necrosis (AVN) as a serious complication of PFO has been reported in the literature. ${ }^{13}$ In contrast to this, no patients in this series showed AVN during the documented follow-up period based on the length of control achieved by the plate system and proper application of the surgical technique, as described by Joeris et al. ${ }^{9}$
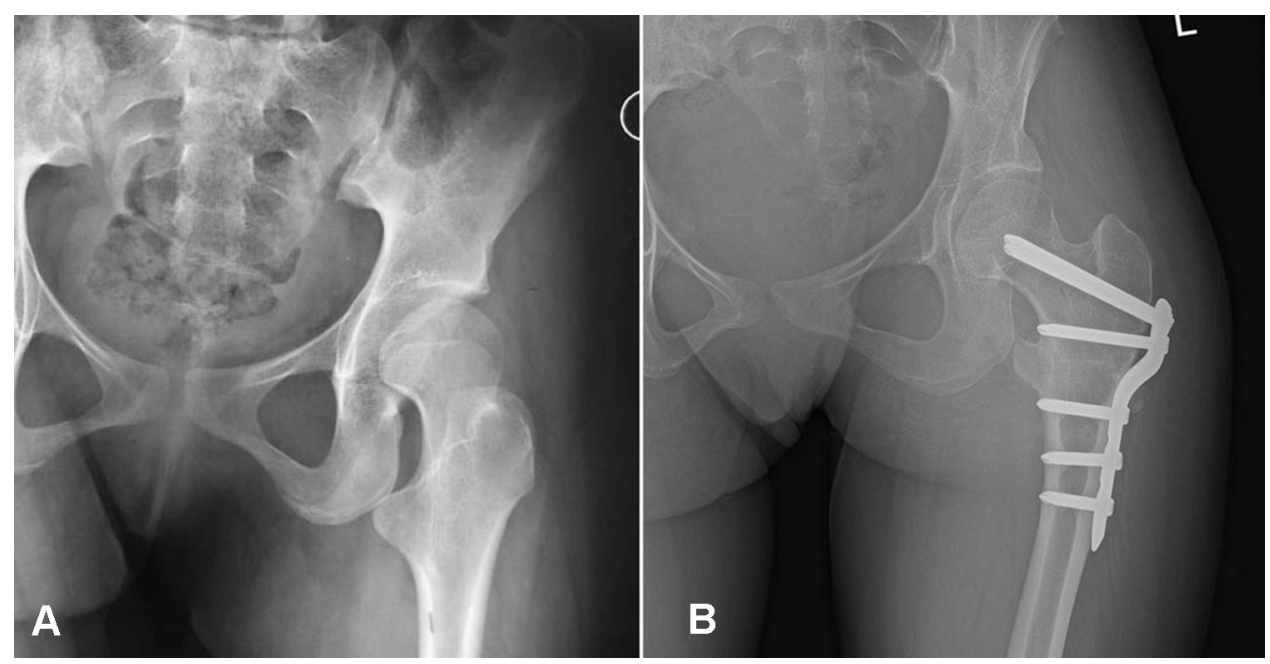

Figure I (A) Preoperative left hip X-ray of cerebral palsy patient GFMCS III. (B) Eight years post PFO using the Pediatric LCP Hip Plate (patient number I9, Table I). 

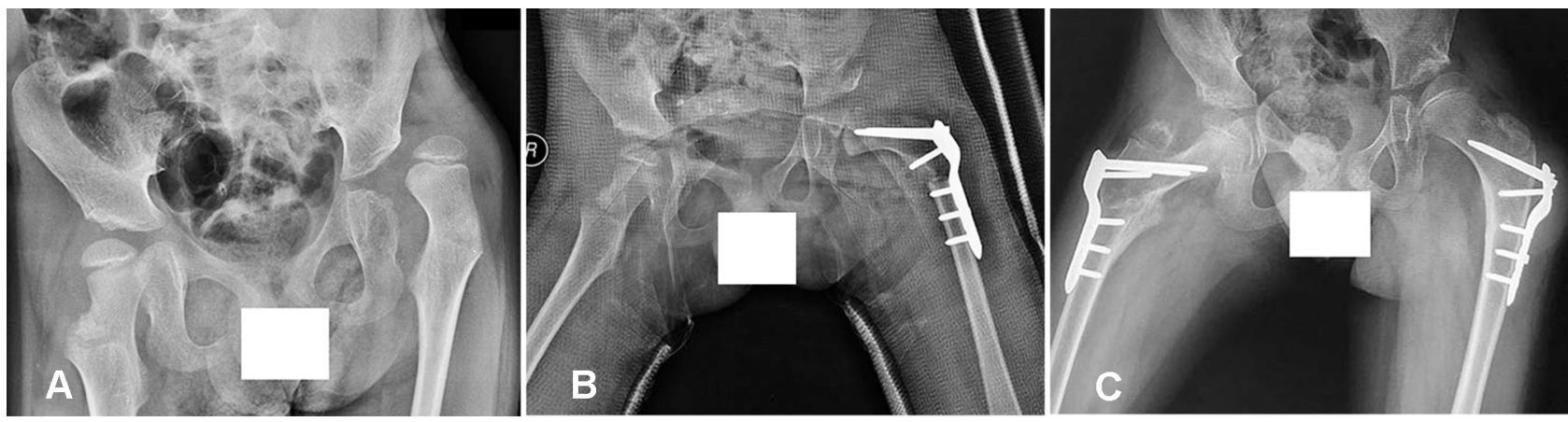

Figure 2 (A) Preoperative pelvis X-ray of cerebral palsy patient GFMCS V. (B) immediate postoperative X-ray of left hip. (C) Final pelvis X-ray of bilateral PFO using the Pediatric LCP Hip Plate (patient number 8 and 9, Table I).

Limitations of this study are the retrospective design, the relatively small number of enrolled patients and the short follow-up period.

\section{Conclusions}

LCP pediatric hip plates are safe implants to fix PFOs in $\mathrm{CP}$ patients. The plate provides a strong stable fixation on osteoporotic bone. With proper planning, different plate designs and locking with screw angular stability, PFOs can be carried out with a negligible complication rate.

\section{Disclosure}

The authors report no conflicts of interest for this work.

\section{References}

1. Soo B, Howard JJ, Boyd RN, et al. Hip displacement in cerebral palsy. J Bone Jt Surg - Ser A. 2006. doi:10.2106/JBJS.E.00071

2. Larnert $P$, Risto $O$, Hägglund G, Wagner P. Hip displacement in relation to age and gross motor function in children with cerebral palsy. J Child Orthop. 2014;8:129-134. doi:10.1007/s11832-014-0570-7

3. Khouri N, Khalife R, Desailly E, Thevenin-Lemoine C, Damsin JP. Proximal femoral osteotomy in neurologic pediatric hips using the locking compression plate. J Pediatr Orthop. 2010;825-831. doi:10.1097/BPO.0b013e31820156f2

4. Chang FM, May A, Faulk LW, et al. Outcomes of isolated varus derotational osteotomy in children with cerebral palsy hip dysplasia and predictors of resubluxation. J Pediatr Orthop. 2018;38:274-278. doi:10.1097/BPO.0000000000000809.
5. Webb JA, Almaiyah M, McVie J, Montgomery RJ. Proximal femoral osteotomies in children using the Richards hip screw: techniques, outcome and subsequent removal. J Child Orthop. 2008;2:417-423. doi:10.1007/s11832-008-0127-8

6. Rutz E, Brunner R. The pediatric LCP hip plate for fixation of proximal femoral osteotomy in cerebral palsy and severe osteoporosis. J Pediatr Orthop. 2010;30:726-731. doi:10.1097/ BPO.0b013e3181efb86b

7. Sidler-Maier CC, Reidy K, Huber H, Dierauer S, Ramseier LE. LCP $140^{\circ}$ pediatric hip plate for fixation of proximal femoral valgisation osteotomy. J Child Orthop. 2014;8:29-35. doi:10.1007/s11832-0140550-y

8. Beauchesne R, Miller F, Moseley C. Proximal femoral osteotomy using the ao fixed-angle blade plate. $J$ Pediatr Orthop. 1992;12:736-740. doi:10.1097/01241398-199211000-00007

9. Joeris A, Audigé L, Ziebarth K, Slongo T. The locking compression paediatric hip plate ${ }^{\mathrm{TM}}$ : technical guide and critical analysis. Int Orthop. 2012;36:2299-2306. doi:10.1007/s00264-012-1643-1

10. Islam SU, Henry A, Khan T, Davis N, Zenios M. The outcome of paediatric LCP hip plate use in children with and without neuromuscular disease. Musculoskelet Surg. 2014;98:233-239. doi:10.1007/ s12306-013-0308-6

11. Hau R, Dickens DRV, Nattrass GR, O'Sullivan M, Torode IP, Graham HK. Which implant for proximal femoral osteotomy in children? A comparison of the AO (ASIF) $90^{\circ}$ fixed-angle blade plate and the richards intermediate hip screw. $J$ Pediatr Orthop. 2000;20:336-343. doi:10.1097/01241398-200005000-00013

12. Ruzbarsky JJ, Beck NA, Baldwin KD, Sankar WN, Flynn JM, Spiegel DA. Risk factors and complications in hip reconstruction for nonambulatory patients with cerebral palsy. $J$ Child Orthop. 2013;7:487-500. doi:10.1007/s11832-013-0536-1

13. Stasikelis PJ, Ridgeway SR, Pugh LI, Allen J. Epiphyseal changes after proximal femoral osteotomy. J Pediatr Orthop Part B. 2001. doi:10.1097/01202412-200110010-00005
Journal of Multidisciplinary Healthcare

\section{Publish your work in this journal}

The Journal of Multidisciplinary Healthcare is an international, peerreviewed open-access journal that aims to represent and publish research in healthcare areas delivered by practitioners of different disciplines. This includes studies and reviews conducted by multidisciplinary teams as well as research which evaluates the results or conduct of such teams or healthcare processes in general. The journal covers a very wide range of areas and welcomes submissions from practitioners at all levels, from all over the world. The manuscript management system is completely online and includes a very quick and fair peer-review system. Visit http://www.dovepress.com/testimonials. php to read real quotes from published authors. 